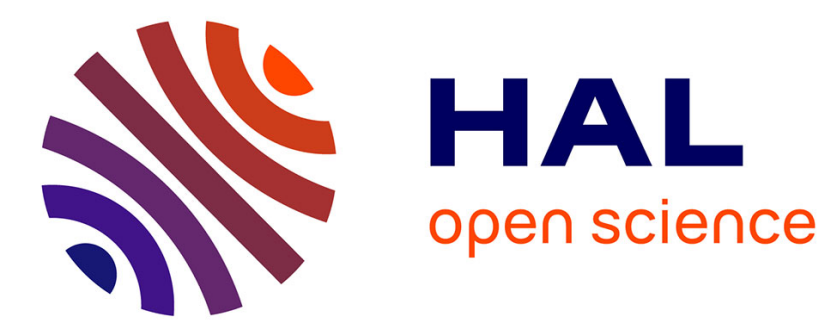

\title{
Quantification of the specific yield in a two-layer hard-rock aquifer model
}

Véronique Durand, Véronique Léonardi, Ghislain de Marsily, Patrick

Lachassagne

\section{To cite this version:}

Véronique Durand, Véronique Léonardi, Ghislain de Marsily, Patrick Lachassagne. Quantification of the specific yield in a two-layer hard-rock aquifer model. Journal of Hydrology, 2017, 551, pp.328-339. 10.1016/j.jhydrol.2017.05.013 . hal-01537837

\section{HAL Id: hal-01537837 https://hal.sorbonne-universite.fr/hal-01537837}

Submitted on 13 Jun 2017

HAL is a multi-disciplinary open access archive for the deposit and dissemination of scientific research documents, whether they are published or not. The documents may come from teaching and research institutions in France or abroad, or from public or private research centers.
L'archive ouverte pluridisciplinaire HAL, est destinée au dépôt et à la diffusion de documents scientifiques de niveau recherche, publiés ou non, émanant des établissements d'enseignement et de recherche français ou étrangers, des laboratoires publics ou privés. 


\section{Quantification of the specific yield in a two-layer hard-rock}

\section{aquifer model}

\section{Véronique Durand ${ }^{(1)}$, Véronique Léonardi ${ }^{(2)}$, Ghislain de Marsily ${ }^{(3)}$, Patrick}

(1) Laboratoire GEOPS; Univ. Paris-Sud; CNRS, UMR 8148; Bât. 504, 91405 Orsay Cedex, France;

\section{veronique.durand@u-psud.fr}

(2) Laboratoire Hydrosciences; Université de Montpellier; CNRS, UMR 5569; CC57, 163 rue Auguste Broussonet, 34090 Montpellier, France; veronique.leonardi@umontpellier.fr

(3) Laboratoire Metis; Sorbonne Universités, UPMC Univ. Paris 06; CNRS, UMR 7619; EPHE; 4 place Jussieu, 75005 Paris, France; gdemarsily@aol.com

(4) Water Institute by Evian, Danone Waters, Evian-Volvic World, BP 87, 74500 Evian-les-Bains Cedex, France; patrick.lachassagne@danone.com

\section{Abstract}

Hard Rock Aquifers (HRA) have long been considered to be two-layer systems, with a mostly

capacitive layer just below the surface, the saprolite layer and a mainly transmissive layer underneath, the fractured layer. Although this hydrogeological conceptual model is widely accepted today within the scientific community, it is difficult to quantify the respective storage properties of each layer with an equivalent porous medium model. Based on an HRA field site, this paper attempts to quantify in a distinct manner the respective values of the specific yield (Sy) in the saprolite and the fractured layer, with the help of a deterministic hydrogeological model. The study site is the Plancoët migmatitic aquifer located in north-western Brittany, France, with piezometric data from 36 observation wells surveyed every two weeks for eight years. Whereas most of the piezometers (26) are located where the water table lies within the saprolite, thus representing the specific yield of the unconfined layer (Sy1), 10 of them are representative of the unconfined fractured layer (Sy2), due to 
their position where the saprolite is eroded or unsaturated. The two-layer model, based on field observations of the layer geometry, runs with the MODFLOW code. 81 values of the Sy1/Sy2 parameter sets were tested manually, as an inverse calibration was not able to calibrate these parameters. In order to calibrate the storage properties, a new quality-of-fit criterion called "AdVar" was also developed, equal to the mean squared deviation of the seasonal piezometric amplitude variation. Contrary to the variance, AdVar is able to select the best values for the specific yield in each layer. It is demonstrated that the saprolite layer is about 2.5 times more capacitive than the fractured layer, with Sy1=10\% $(7 \%<$ Sy $1<15 \%)$ against Sy $2=4 \%(3 \%<$ Sy $2<5 \%)$, in this particular example.

\section{Keywords}

Hard-rock aquifer; Specific yield; Two-layer numerical model; Quality-of-fit criterion

\section{Highlights}

- Quantitative evidence that the saprolite layer is more capacitive than the fractured one - New quality-of-fit criterion, AdVar, based on the piezometric amplitude variations

\section{Introduction}

Hard-Rock aquifers (HRA) have long been considered to be two-layer systems, with (i) a weakly transmissive but rather capacitive layer (with a high specific yield) just below the surface, the unconsolidated weathered layer (also called the saprolite here, or the regolith) and (ii) a more transmissive but less capacitive layer underneath, the fractured layer. This hydrogeological conceptual model is now widely accepted in the scientific community (see for instance Chilton and Foster, 1995; Cho et al., 2003; Dewandel et al., 2006; Dewandel et al., 2011; Lachassagne et al., 2011; McFarlane, 1992; Taylor and Howard, 1999, 2000; Wright, 1992). These two layers belong to the HRA weathering profile and reach, in general, a thickness that may exceed $100 \mathrm{~m}$ (Lachassagne et al., 2011). At the watershed scale, the hydrodynamic storage and flow properties of the underlying 
unfractured rocks (basement) are negligible. The capacitive (or storage) properties of this two-layer system, namely its storativity, or specific yield Sy where the aquifer is unconfined, were first studied and characterized to gain a better estimate of the long-term groundwater storage available in HRAs. It was established early on that the fractures in HRAs are well connected (Lenck, 1977) and later, that this fractured layer could be considered a continuous aquifer (Guihéneuf et al., 2014; Lachassagne et al., 2001). Some studies have focused on the specific yield of the saprolite layer, and consequently on the capacitive role it can play during withdrawals (Detay et al., 1989; Howard and Karundu, 1992; Rushton and Weller, 1985). The processes controlling the development of these two layers are increasingly well understood and the ways to define their respective geometry and thickness are more precise (Dewandel et al., 2006; Lachassagne et al., 2011; Wyns et al., 2004); moreover, pumping test methods to characterize their hydrodynamic properties at the borehole scale have been improved (Maréchal et al., 2004). However, the precise determination of the respective storage properties of each layer remains an issue, particularly at the watershed scale (Dewandel et al., 2012).

A number of authors have modelled these systems as equivalent porous media, but none of them has managed to calibrate the specific yield of both layers simultaneously. Gupta et al. (1985) used a single-layer model, considering that both layers were interconnected. Ahmed et al. (2008) presented a two-layer model calibrated on an Indian site, but unfortunatly the saprolite layer was always unsaturated, which made it impossible to calibrate its specific yield. An interesting specific yield calibration for a two-layer model of an HRA is presented in Lubczynski and Gurwin (2005), but the paper did not focus on this parameter, so that the specific yield values were not presented, nor the potential differences between the saprolite and the fractured layer. The authors point out the difficulty in calibrating the specific yield with an automatic inverse method like PEST, and prefer a trial-and-error calibration, in order to "have the best fit of the pattern of rises and recessions of the groundwater table". The same kind of difficulty was also highlighted by Mazi et al. (2004), where to calibrate the specific yield, the authors needed the help of an expert as a complement to the 
automatic calibration. In fact, automatic calibration methods are mainly focused on the hydraulic conductivities, adjusted with the help of a quality-of-fit criterion based on the differences between the modelled and observed hydraulic heads (Carrera et al., 2005; de Marsily et al., 2000; Zhou et al., 2014). For aquifer management purposes, a correct quantification of the distinct specific yields of the two layers is important, as a potentially highly capacitive layer represented by the saprolite may sustain the exploited water resources in the fractured layer.

In this context, the main objective here is to calibrate the specific yield in each of the two layers of a finite-difference hydrogeological model, at the watershed scale. This parameter, representative of the storage properties, is crucial in groundwater management purposes. Because of the difficulties mentioned above, this calibration required the development of a new quality-of- fit criterion. This study uses field data from an HRA in Brittany, France, described in the following section. The model is then presented, followed by the calibration (approach and results). The results are discussed, and a conclusion summarizes the main results of the study.

\section{Geology and hydrogeology of the study site}

\subsection{General presentation}

The studied site (Durand et al., 2006) is located in north-eastern Brittany, France, $10 \mathrm{~km}$ from the English Channel shoreline (Figure 1), in a landscape of grass-land, forest and farmland, with a smooth relief. In the middle of the studied site stands a $90 \mathrm{~m}$ ASL hill, surrounded by the Arguenon River at $10 \mathrm{~m}$ ASL flowing toward the English Channel (Figure 1). The migmatites that constitute the rocks in this area belong to the Saint-Malo dome, exhumed at the end of the Cadomian Orogeny (540 Ma). These partially melted rocks originated from detrital sediments interbedded with graphitic cherts, composed of quartz. They now form a folded gneiss with relict bands of cherts. They were later intruded by dolerite dykes during the Hercynian period (330 Ma). The associated hard-rock aquifer is located mostly in the sub-surface stratiform weathered layers (Durand et al., 2006), which consist of: (i) a cover of unconsolidated weathered rocks (saprolite), several tens of meters thick where it has 
been preserved from erosion, consisting mainly of clay or sandy clay, that are the weakly permeable transformation products of the initial minerals; (ii) beneath this layer, and above the unweathered bedrock, a fractured layer, some $50 \mathrm{~m}$ thick or more, resulting from rock shattering under the influence of stress generated by the swelling of certain minerals during the early stages of weathering (Dewandel et al., 2006; Lachassagne et al., 2011; Wyns et al., 2004). Field surveys and geophysical mapping of the two weathered-fractured layers and of the various geological heterogeneities, such as graphitic cherts and dolerite dykes, are described in a previous study (Durand et al., 2006). In an area covering only $4 \mathrm{~km}^{2}$, six pumping wells and 36 piezometers (Error!

Reference source not found.), owned and monitored by the Nestlé Waters Company for bottled natural mineral and spring water, provide an unusually rich set of hydrogeological data. While most piezometers (26) are located where the saprolite is saturated, and will thus help to quantify the storage in this layer, 10 of them are located where the saprolite is either eroded, or unsaturated, and will consequently help the storage quantification in the fractured layer.

Figure 1. Location of the study area (within the grey-shaded polygon), the meteorological stations (stars), and the only gauging station (square)

Figure 2. Geometry of the finite-difference model, boundary conditions, thickness of layer 1 (white: zero thickness) and location of the piezometers with their respective numbers

\subsection{Recharge estimation}

The daily rainfall was measured directly at the Plancoët bottling plant (Figure 1). The mean annual rainfall (R) is on average $800 \mathrm{~mm}$, with a typical oceanic climate. Around Plancoët, three weather stations belonging to Météo France, located in Pleurtuit, Quinténic and Trémeur (Figure 1), also provided data on rainfall and daily potential evapotranspiration (PET) estimated with Penman's relation (Penman, 1948). Daily river flow measurements were available at the Jugon-les-Lacs gauging 
station (Figure 1) on the Arguenon River, which drains the studied area. Over the eight years of the monitored period, a mean annual river discharge of $253 \mathrm{~mm} / \mathrm{y}$ was found at the Jugon-les-Lacs gauging station, for the area of its catchment (see Durand (2005) for more details). Thornthwaite's method (Castany, 1967; Maidment, 1993; Vittecoq et al., 2010) was used at a daily time step and during the eight-year monitored period to compute the effective rainfall $\left(E f f_{R}\right)$, equal to $P$ minus Real EvapoTranspiration (RET), or to the sum of the aquifer recharge plus the surface runoff over the catchment. The computation used the rainfall data measured directly on the Plancoët site, and the weighted average of PET data from the three Météo France weather stations calculated for the site.

The maximum soil storage capacity (MSC), the parameter used in Thornthwaite's method to temporarily store rainfall in the soil before it is taken up by RET and $\mathrm{Eff}_{\mathrm{R}}$, was calibrated so that the $\mathrm{Eff}_{\mathrm{R}}$ value would be as close as possible to the available annual catchment flow in the area. In this hydrogeological context, both runoff and aquifer recharge reach the river in a year (Molénat et al., 1999). Rounding off the value, the best fit for MSC was obtained with $100 \mathrm{~mm}$, leading to a mean real evapotranspiration of $530 \mathrm{~mm} / \mathrm{y}$ and an annual effective rainfall of $247 \mathrm{~mm} / \mathrm{y}$, quite close to the average river discharge. Figure 3 presents the meteorological data $\left(\mathrm{P}, \mathrm{RET}\right.$ and $\left.\mathrm{Eff}_{\mathrm{R}}\right)$ averaged for each model time step in $\mathrm{mm} /$ day. It shows that EffR is positive only during the winter season, when RET is sufficiently low. Considering the landscape, smooth relief and grassy hills, the field observations during the winter rainy season (no runoff observed even during the most intense rainy periods), and for simplicity reasons, the recharge was fixed at $100 \% \mathrm{Eff}_{\mathrm{R}}$. This will be discussed in the final discussion part below.

Figure 3. Precipitation (P), calculated real evapotranspiration (RET) and effective rainfall $\left(E_{R}\right)$ used for each model time-step

\subsection{Water table variations}

The piezometric signals in this type of aquifer, in a temperate climate, have a pseudo-sinusoidal shape with an annual period, where the highest levels are observed at the end of winter and the 
lowest at the end of summer. The amplitude of the head variations between the high and low levels depends both on the time distribution of the recharge and on the Sy values (Maréchal et al., 2006). As the specific yield plays an active role only for an unconfined layer, it is either Sy in the saprolite layer 1 (Sy1) or Sy in the fractured layer 2 (Sy2) that is effective, depending on the piezometer location: Sy1 is effective where layer 1 (saprolite layer) is present and saturated (26 piezometers), and Sy 2 will be effective where layer 1 has been eroded or is unsaturated (10 piezometers). In the data set, both piezometer types are well represented, and it is interesting to compare the signals obtained for each type. The piezometric head was measured manually in each observation hole from $1 / 1 / 1996$ to $30 / 11 / 2003$, with a time step of approximately 15 days. From these data, one can see that the mean annual amplitude variation of the piezometric levels is higher in the piezometers representing layer 2 , the fractured layer $(6.1 \pm 2.3 \mathrm{~m}$ in average) than in those representing layer 1 , the saprolite (3.4 $\pm 1.3 \mathrm{~m}$ in average). An example is shown in Figure 4 .

Figure 4. Measured water table in two types of piezometers: P17 in the fractured layer and P26 in the saprolite

\section{Model description}

The finite-difference PMWIN model (Chiang and Kinzelbach, 2000) that uses the MODFLOW code (Harbaugh and McDonald, 1996) was chosen for this work. The model was built with two parallel layers in order to account for the assumed distinct hydrodynamic properties of the saprolite (layer 1), and the underlying weathered fractured layer (layer 2).

The geometry of each of these layers (shape of top and bottom) was determined by extensive field work over the entire $116 \mathrm{~km}^{2}$ study area (Durand et al., 2006). The maximum thickness of layer 2 , where it is totally preserved from erosion, was found to be quite uniform across the studied area and was estimated at $100 \mathrm{~m}$, a thickness consistent with our experience of the Brittany geology and the 
available borehole logs and geophysical data (Durand, 2005). Layer 2 is present over the whole modelled area $\left(116 \mathrm{~km}^{2}\right)$, as it has never been totally eroded, whereas layer 1 , with a maximum thickness of $40 \mathrm{~m}$, covers only $54 \mathrm{~km}^{2}$, due to local patches of total erosion (Error! Reference source not found.).

In the centre of the modelled area, owned by Nestlé Waters and including the bottled-water exploitation zone, the accuracy of the structural map and the number of hydrogeological data are much higher than in the other areas. The rectangular grid of the model (Error! Reference source not found.) is therefore a compromise between good precision where the data are dense and relatively fast calculations: consequently, the width of the rectangular model cells varies from $400 \mathrm{~m}$ on the borders to $40 \mathrm{~m}$ in the exploitation zone. Each of the two layers is modelled vertically by a single cell whose height is equal to the thickness of the corresponding layer. The layers are connected vertically, as they are assumed to be in reality. Layer 1 is modelled as an unconfined aquifer and layer 2 can be either confined or unconfined, depending on the potential lowering of the piezometric head below the bottom of layer 1.

The simulations were performed in a transient flow regime which allowed the time-dependent seasonal and yearly piezometric variations observed in the aquifer to be reproduced. The modelling runs from $1 / 1 / 1996$ to $30 / 11 / 2003$, with a time step of 15 days, similar to the frequency of the piezometric head measurements.

Six pumping wells in the exploitation zone (Error! Reference source not found.) are used for bottledwater production and their time-varying discharges are precisely recorded and used in the model. No other significant pumping is known to occur in the whole modelled domain, except a few tens of litres per day, in the summer, from shallow wells, not considered in this study.

The total modelled domain, chosen much larger than the area exploited by the bottling plant, is limited by permanent rivers, considered to be prescribed-head boundaries, so no conductance parameter was set for these cells (Error! Reference source not found.). The river elevations were extracted from the 1/25 000 topographic map of the area (IGN, 2000) assuming a linear slope 
between known points (contour lines every $5 \mathrm{~m}$ ). In the exploitation zone, the topographic depression due to a disused quarry of graphitic cherts located near the top of a hill is at the origin of a small perennial lake (Error! Reference source not found.). The level of this lake, generally higher than that of the observed nearby piezometric levels, shows that it functions as an infiltration zone. It is modelled as a reservoir in the MODFLOW code (Error! Reference source not found.), with a prescribed constant level, a water depth of $1 \mathrm{~m}$, and an underlying $1 \mathrm{~m}$-thick sediment layer with a vertical hydraulic conductivity of $1.210^{-5} \mathrm{~m} / \mathrm{s}$. This value was calibrated so that the infiltration from the lake is consistent with its hydrological balance. Two small temporary rivers (Error! Reference source not found.) surrounding the hill are considered as drains in the model, because they drain the aquifer during high-water periods and are dry during the rest of the year. A calibrated hydraulic conductance of $5.810^{-4} \mathrm{~m}^{2} / \mathrm{s}$ was assigned to the contact area between the aquifer and these drains. The initial value of the piezometric heads on January $1^{\text {st }}, 1996$ was estimated as follows: a preliminary run of the model over the whole 8-year period started with heads at the ground surface; the calculated heads on November $3^{\text {rd }}, 2003$ at the end of this preliminary run were then taken as the initial conditions for January $1^{\text {st }}, 1996$.

\section{Calibration}

\subsection{Homogeneous model calibration}

In this type of aquifer, the hydraulic conductivity might be very heterogeneous; but the heterogeneity does not depend primarily on the geometry of the two layers, but rather on the location of fractures and other spatial discontinuities. As this type of heterogeneities was not the main focus here, a homogeneous hydraulic conductivity was chosen for each layer, and the PEST automatic calibration method in transient state (Doherty, 2004), within the PMWIN interface, was used to provide the best possible average fit. In a first approximation, the hydraulic conductivity and the specific yield, considered here to be uniform in space and identical for the two layers, were calibrated simultaneously: the best calibrated hydraulic conductivity was $8.110^{-7} \mathrm{~m} / \mathrm{s}$, and the 
$252 \operatorname{Var}=\frac{\sum_{\mathrm{d}=1}^{\mathrm{n}}\left[\mathrm{calc}_{\mathrm{d}}-\mathrm{obs}_{\mathrm{d}}\right]^{2}}{\mathrm{n}}$

specific yield was $6 \%$. An arbitrary value of the storage coefficient for the confined layer was set at $10^{-4}$. As the hydraulic conductivity is only roughly calibrated on the whole model, the simulated heads are therefore shifted locally, as compared to the observed ones. It is considered that this shift does not influence the further calibration of Sy1 and Sy2, based on a good amplitude variation fit. This specific point is discussed in the final discussion part of the article.

\subsection{Classical calibration of the specific yield using the variance criterion}

In a second step, a model with distinct storage properties in the two layers was used to obtain a better calibration of the specific yield (Sy). This hydraulic parameter may be considered the most important one in the two-layer model. Contrary to the hydraulic conductivity, which influences the average hydraulic heads, this parameter influences primarily the amplitude of the hydraulic-head variations. We used PEST for an automatic calibration of Sy1 and Sy2, fixing the previously calibrated value for the hydraulic conductivity. Sy1 was found to be optimum at 3\%, but the Sy2 calibrated values were always the maximum defined ones, even when amounting to $50 \%$. This can be explained by the fact that, due to the imperfect calibration of the hydraulic conductivity of the model, the average simulated head values are shifted as compared to observed data, and that the quality-of-fit criterion used in PEST is the least squares of the differences between modelled and observed heads. As a high Sy tends to reduce the amplitude variation of the signal, the quality-of-fit criterion is better with a "flat" signal than a varying one in the case where the general average is very different from the true one. In order to understand the automatic calibration process, and to quantify the performance of each model, various combinations of Sy parameters were tested manually. Nine values of Sy 1 and Sy 2 were thus tested (1\%, 2\%, 3\%, 4\%, 5\%, 6\%, 7\%, 10\% and $15 \%)$, leading to 81 model runs. The classical head squared deviation variance (Var, Equation 1) between the calculated $\left(\right.$ calc $\left._{d}\right)$ and observed heads $\left(\right.$ obs $\left._{d}\right)$ on each measurement day of the data set was calculated for all 36 piezometers and this variance was averaged over the whole data set for each model.

with $\mathrm{n}$ the number of data points for each piezometer. 
Note that in PEST, the sum of squared deviation is used, but here we take into account the number of measurements over periods of varying lengths in order to compare the results obtained for each piezometer. Considering all piezometers, the best Var value was $97 \mathrm{~m}^{2}$ for Sy $1=3 \%$ and $\mathrm{Sy} 2=15 \%$. Nevertheless, it appeared that these statistics might be biased by the fact that some simulated heads concerned another layer than the one of the observed data (for instance, the observed piezometry is in the saprolite while the computed one is in the fractured layer, or vice-versa). As the hydraulic conductivity was not calibrated, this was observed on 7 piezometers representative of the saprolite, and on 4 from the fractured layer. In order to avoid this specific bias and improve the results, we chose to remove these piezometers and re-calculate the average Var values. The results obtained for the various Sy values are given in matrix form (Table 1), the values of Var are shown with Sy1 values in columns and Sy2 values in rows. The minimum Var values are highlighted (corresponding to the better fit). Table 1 shows that the coloured cells are below the diagonal matrix, i.e. for Sy2>Sy1, and that the maximum chosen Sy2 value (15\% here) leads to the better Var value. This confirms that, for the same reasons as explained above, the Var criterion, or any criterion based on squared head deviations, as in PEST, is not appropriate for the calibration of Sy. It is therefore necessary to develop another criterion better adapted to calibrate Sy in each layer.

Table 1. Var values (in $\mathrm{m}^{2}$ ) obtained for all Sy1 and Sy2 values. Yellow: minimum values; orange, red and light brown respectively: classes around the minimum, with an increase of Var of $5 \%$ of the total variation range between two successive classes

\subsection{New calibration of the specific yield taking the amplitude variation into account}

To better fit the specific yield, a new performance criterion, named "AdVar", was developed, based on the seasonal piezometric amplitude variations. For each piezometer, and for each available measurement on day $d$, a moving interval of one year after $d$ was defined both for the observed and 
the calculated heads. Then for that one-year interval, each piezometer amplitude-deviation variance AdVar is defined as the average of the squared amplitude deviations, i.e.:

$\operatorname{AdVar}=\frac{\sum_{\mathrm{d}=1}^{n_{\text {day }}}\left[\left(\max _{\text {calc }_{d}}-\min _{\text {calc }_{d}}\right)-\left(\max _{\text {obs }_{d}}-\min _{\text {obs }_{d}}\right)\right]^{2}}{n_{\text {day }}}$

with $\max _{\text {calcd }}, \min _{\text {calcd }}, \max _{\text {obsd }}, \min _{\text {obsd }}$ respectively the maximum-minimum values of the calculated and observed heads over the one-year interval after day $d$, and $n_{\text {day }}$ the number of measurement dates $d$ available, i.e. the total number of data points less those of the last year of data. Like the variance, AdVar is always positive and the smaller values indicate a better fit. For a better visualisation of the AdVar behaviour compared to Var, when quantifying the fit between theoretical sinusoidal curves, please refer to Appendix 1.

Considering all piezometers, the best AdVar value was $9.7 \mathrm{~m}^{2}$ for Sy $1=10 \%$ and Sy $2=4 \%$. Removing the biased piezometers as previously, and re-calculating the average AdVar values, the same matrix form as for Var was used for AdVar in 2, with Sy1 values in columns and Sy2 values in rows. 2 shows that the coloured cells are above the diagonal matrix, i.e. for Sy1>Sy2, with AdVar, which seems more realistic from a hydrogeological viewpoint than the results obtained with Var. Following this criterion, the specific yield is about $10 \%$ in the saprolite (Sy1) and $2 \%$ in the fractured layer (Sy2). The uncertainty intervals are $7 \%<$ Sy $1<15 \%$ and $1 \%<$ Sy $2<3 \%$.

Table 2. AdVar values (in $\mathrm{m}^{2}$ ) obtained for all Sy1 and Sy2 values. Yellow: minimum values; orange, red and light brown respectively: classes around the minimum, with an increase of AdVar of $0.5 \%$ of the total variation range between two successive classes

\subsection{Comparison of the simulated water tables from the best adjustments of Var and AdVar}

To give a better view of the results obtained in each of the two layers of the model, Figure 5 shows the observed piezometric variations compared with two simulations in P26, a piezometer 
representative of the saprolite layer, and in P17, representative of the fractured layer. The first model, with Sy $1=2 \%$ and Sy $2=15 \%$, corresponds to the best performance for the Var criterion, and the second model, with Sy $1=10 \%$ and Sy $2=2 \%$, to the best performance for the AdVar criterion. Even if the hydraulic conductivity, and thus the mean value of the piezometric head is not perfectly fitted, the second model with the lowest Sy2 and the highest Sy1 better mimics the observed amplitude variations than the first one, with low Sy1 and high Sy2 values.

The Var and AdVar values are given in Table 3 for each of these piezometers with the two above models. Except for Var in P17, the values follow the same trend as the average Var and AdVar values: the first model gives a better Var, and the second a better AdVar. Between two distinct models, an expert eye would choose in accordance with the AdVar criterion, not with the Var one. As a conclusion to this part of the work, the obtained calibration of Sy can be considered very satisfactory, particularly when one considers that, for this study, no spatial variations neither of the hydraulic conductivity, nor of the specific-yield, were considered.

Figure 5. Examples of piezometric variations for $P 26$ within the saprolite and $P 17$ within the fractured layer. Two model results corresponding to the best Var and AdVar values are compared to the observed data

Table 3. Var and AdVar values (in $\mathrm{m}^{2}$ ) for piezometers $P 26$ and $P 17$ with two Sy set of values

\begin{tabular}{|l|l|l|l|l|}
\hline \multicolumn{2}{|l|l|l|}{ Sy1=2\%, Sy2=15\% } & \multicolumn{2}{l|}{ Sy1=10\%, Sy2=2\% } \\
\hline & Var & AdVar & Var & AdVar \\
\hline P17 & 16.0 & 22.9 & 13.3 & 1.5 \\
\hline P26 & 6.2 & 14.2 & 16.1 & 0.3 \\
\hline
\end{tabular}




\subsection{Comparison of specific yield values with other studies}

324

325

These results of specific yield values are consistent with the conceptual model developed by Lachassagne et al. (2001) and Dewandel et al. (2010), notably with a decrease of Sy with depth. The obtained Sy values (Sy1=10\% and Sy2=4\% for the best AdVar values) are higher than those given by Rushton and Weller (1985) for a granite in India and by Compaore et al. (1997) for a granite in Burkina Faso. These authors estimated the specific yield of the saprolite layer at between 1 and 2\%. Nevertheless, as shown by Wyns et al. (2004), Sy in the saprolite is sensitive to the type of lithology: for instance, Sy increases with the coarsening of the minerals of the parent rock and also with the quartz content. The interval of specific-yield values measured by Wyns et al. (2004) on several types of hard-rock lithologies in Brittany (France) includes the values estimated in the present study.

\subsection{Recharge sensitivity}

In order to simplify the results, the recharge value was fixed arbitrarily in this study, considering that runoff is negligible. Previous work done elsewhere in Brittany (Durand and Juan Torres, 1996; Jiménez-Martinez et al., 2013; Molénat et al., 1999) using other methods, such as isotope and natural tracer analyses, river discharge recession-curve analysis, or temporal groundwater head variations in response to recharge inputs, has arrived at similar conclusions. Nevertheless, it is possible to explore the sensitivity of the model to the recharge, testing various recharge values. Figure 6 shows the observed and simulated heads at P26, for the reference model (Sy1=10\%, Sy $2=4 \%$, Recharge $=100 \% \mathrm{Eff}_{\mathrm{R}}$ ), and for two other models, keeping the same Sy values, and testing Recharge $=70 \% \mathrm{Eff}_{\mathrm{R}}$ and Recharge $=30 \% \mathrm{Eff}_{\mathrm{R}}$. Note that the simulated heads with low recharge values never stop decreasing from the beginning to the end of the simulation, and even drop below the observed values. They also decrease a little with the maximum recharge, due to a problem in the initial head, difficult to calibrate here, but it appears that the average heads tend to stabilize at the end of the modelled period. It is not the case with lower recharge values, leading to the conclusion that these values are too low to provide enough water to the aquifer, compared to the real natural 
discharge and pumping rate on the site. Some graphics showing the Var and AdVar results with a complete parameter set (8 recharge values for each Sy combination) are presented in Appendix 2 .

Figure 6. Observed and modelled heads for P26, testing various recharge values

\subsection{Hydraulic conductivity sensitivity}

In this study, an arbitrary choice was made to leave out the hydraulic conductivity calibration.

Although it is the main parameter of the flow budget within the aquifer, this choice was made in order to focus attention on the storage parameter, a crucial parameter in HRA to quantify the exploitable water resources. The aim was to quantify the specific-yield in the two layers of an HRA, highlighting their differences, and not to build a fully calibrated model for water-resource management purposes. A local adjustment of hydraulic conductivities may induce some minor modification of the temporal head amplitude variations. This is shown in Figure 7 with the example of P26: the reference model (black plain line), with $\mathrm{K}=8.110^{-7} \mathrm{~m} / \mathrm{s}$, is compared to models with $\mathrm{K}=8.1$ $10^{-6} \mathrm{~m} / \mathrm{s}$ (light grey) and $\mathrm{K}=1.210^{-7} \mathrm{~m} / \mathrm{s}$ (dark grey). Changes of $\mathrm{K}$ highly influence the mean interannual piezometric values, but influence in a minimal way the amplitude variations. One can conclude that more reasonable changes in $\mathrm{K}$ than those of this sensitivity analysis, to better fit the local data, would not seriously impact the amplitude variations. It is considered that, in the highdensity data zone where the piezometers are located, the amplitude variations would not be much affected, as the chosen homogenous $\mathrm{K}$ value is already quite well fitted. It is possible, however, that the calibrated Sy values for both layers might not be quite exact, due to the local K variations. But the general tendency toward a higher storage capacity in the saprolite layer than in the fractured one will stay the same, whatever the local $\mathrm{K}$ values.

Figure 7. Observed and modelled heads on $P 26$, testing various $K$ values 


\subsection{Synthesis}

Figure 8 synthesises these results in a qualitative way, presenting the respective behaviours of the saprolite and the fractured layer in two columns. In the case where the water table stays in the saprolite layer (first column), the observed water table (dotted blue line) varies with a low amplitude. The model M1 (in orange), with a high specific yield, well reproduces this low amplitude variation, but presents a computed average head value different from the observed one (lower here), as a consequence of the imperfect $\mathrm{K}$ calibration. Therefore, the variance calculated between the M1 computed red curve and the observed data is high, whereas the AdVar criterion is very good. Still in the first column, the inverse is shown for the model M2 (in green), with a low specific yield: its amplitude variation is too high compared to the observed data, leading to a high AdVar criterion. But as $\mathrm{M} 2$ presents an average value very similar to the observed data, the variance is better than for M1. This first column shows a higher efficiency of the Advar quality-of-fit criterion (rather than the Variance) in identifying the best Sy (here M1 with a high Sy), even if the average head is not well calibrated (for instance because of a locally imperfect calibration of K). Inversely, in the case where the water table stays in the fractured rock (second column), the observed water table varies with a high amplitude. The same M1 model as previously, well fitted for the average head, shows here a good variance criterion, but a weak AdVar criterion. And the same M2 model as previously, with a distinct average head but an amplitude variation similar to the data, shows a weak variance but a good Advar criterion. Again, this second column shows a greater efficiency of the Advar quality-of-fit criterion in identifying the best Sy (here M2 with a low Sy). This emphasises that the ideal model combines $\mathrm{M} 1$ and $\mathrm{M} 2$, with a relatively high specific yield in the saprolite layer, and a lower specific yield in the fractured layer, which are the two main conclusions of this paper. Moreover, the AdVar criterion is better adapted to quantifying the amplitude variation (thus to fit the specific yield) than the Var criterion. 
Figure 8. Schematic view of the main results showing the observed and simulated piezometric amplitude variation for the two cases of a water table in the saprolite and in the fractured layer.

\section{Conclusion}

In this study, a hard-rock aquifer system in Britany (France) was simulated with a two-layer deterministic hydrogeological model at the catchment scale, each layer representing a specific weathering horizon (saprolite and fractured layer). The storage capacities of each layer can be quantified thanks to a rich data set, with piezometers representing the two types of layers, when unconfined. The specific yield values are calibrated using a new quality-of-fit criterion, AdVar, based on the seasonal piezometric amplitude variations. The saprolite layer is proved to be more capacitive than the fractured layer, with a calibrated specific yield 2.5 times greater than that of the fractured layer: Sy $1=10 \%(7 \%<$ Sy $1<15 \%)$ against Sy $2=4 \%(3 \%<$ Sy $2<5 \%)$, in this particular example.

\section{Aknowlegdment}

We are grateful to the Nestlé Waters Company for financial support from 2002 to 2005 and for making the data available.

\section{References}

Ahmed, S., J.-C. Maréchal, E. Ledoux, and G. de Marsily (2008), Groundwater modelling in hard-rock terrain in semi-arid areas: experience from India, in Hydrological Modelling in Arid and Semi-Arid Areas, edited by H. Wheater, S. Sorooshian and K. D. Sharma, International Hydrology Series, Cambridge University Press, Cambridge, UK, p. 157-189.

Carrera, J., A. Alcolea, A. Medina, J. Hidalgo, and L. J. Slooten (2005), Inverse problem in hydrogeology, Hydrogeology Journal, 13, 206-222, doi: 10.1007/s10040-004-0404-7.

Castany, G. (1967), Traité pratique des eaux souterraines, Dunod ed., 661 p., Paris.

Chiang, W. H., and W. Kinzelbach (2000), 3D-Groundwater Modeling with PMWIN - A Simulation System for Modeling Groundwater Flow and Pollution, 346 p., Berlin Heidelberg New York. 
Chilton, P. J., and S. S. D. Foster (1995), Hydrogeological Characterisation And Water-Supply Potential Of Basement Aquifers, Tropical Africa Hydrogeology Journal, 3, 36-49.

Cho, M., K. M. Ha, Y.-S. Choi, W. S. Kee, P. Lachassagne, and R. Wyns (2003), Relationships between the permeability of hard-rock aquifers and their weathered cover based on geological and hydrogeological observations in South-Korea, paper presented at IAH Conference on "Groundwater in fractured rocks", Prague, 15-19 September 2003.

Compaore, G., P. Lachassagne, T. Pointet, and Y. Travi (1997), Evaluation du stock d'eau des altérites. Expérimentation sur le site granitique de Sanon (Burkina-Faso), paper presented at Hard Rock Hydrosystems, IAHS, Rabat, may 1997.

de Marsily, G., J.-P. Delhomme, A. Coudrain-Ribstein, and M. A. Lavenue (2000), Four decades of inverse problems in hydrogeology, in Theory, Modeling, and Field Investigation in Hydrogeology: A Special Volume in Honor of Shlomo P. Neuman's 60th Birthday, edited by D. Zhang and C. L. Winter, Geological Society of America Special Paper, Boulder, Colorado, p. 1-17.

Detay, M., P. Poyet, Y. Emsellem, A. Bernardi, and G. Aubrac (1989), Influence du développement du réservoir capacitif d'altérites et de son état de saturation sur les caractéristiques hydrodynamiques des forages en zone de socle cristallin, Comptes rendus de l'Académie des Sciences de Paris, Série II a, 309, 429-436.

Dewandel, B., P. Lachassagne, R. Wyns, J.-C. Maréchal, and N. S. Krishnamurthy (2006), A generalized 3-D geological and hydrogeological conceptual model of granite aquifers controlled by single or multiphase weathering, Journal of Hydrology, 330, 260-284, doi: 10.1016/j.jhydrol.2006.03.026.

Dewandel, B., P. Lachassagne, F. K. Zaidi, and S. Chandra (2011), A conceptual hydrodynamic model of a geological discontinuity in hard rock aquifers: Example of a quartz reef in granitic terrain in South India, Journal of Hydrology, 405, 474-487, doi: 10.1016/j.jhydrol.2011.05.050.

Dewandel, B., J.-C. Maréchal, O. Bour, B. Ladouche, S. Ahmed, S. Chandra, and H. Pauwels (2012), Upscaling and regionalizing hydraulic conductivity and effective porosity at watershed scale in deeply weathered crystalline aquifers, Journal of Hydrology, 416-417, 83-97, doi: 10.1016/j.jhydrol.2011.11.038.

Dewandel, B., J. Perrin, S. Ahmed, S. Aulong, Z. Hrkal, P. Lachassagne, M. Samad, and S. Massuel (2010), Development of a tool for managing groundwater resources in semi-arid hard rock regions. Application to a rural watershed in south India, Hydrological Processes, 24, 2784-2797, doi: 10.1002/hyp.7696.

Doherty, J. (2004), PEST: Model Independent Parameter Estimation. Fifth edition of user manual, Watermark Numerical Computing, Brisbane, Australia.

Durand, P., and J. L. Juan Torres (1996), Solute transfer in agricultural catchments: the interest and limits of mixing models, Journal of Hydrology, 181, 1-22. 
Durand, V. (2005), Recherche multidisciplinaire pour caractériser deux aquifères fracturés : les eaux minérales de Plancoët en contexte métamorphique, et de Quézac en milieu carbonaté, unpublished PhD thesis, 255 pp, Université Pierre et Marie Curie, Paris, doi: <tel-00083473v2>.

Durand, V., B. Deffontaines, V. Léonardi, R. Guérin, R. Wyns, G. de Marsily, and J.-L. Bonjour (2006), A multidisciplinary approach to determine the structural geometry of hard-rock aquifers. Application to the Plancoët migmatitic aquifer (NE Brittany, W France), Bulletin de la Société Géologique de France, 177, 227-237.

Guihéneuf, N., A. Boisson, O. Bour, B. Dewandel, J. Perrin, A. Dausse, M. Viossanges, S. Chandra, S. Ahmed, and J.-C. Maréchal (2014), Groundwater flows in weathered crystalline rocks: Impact of piezometric variations and depth-dependent fracture connectivity, Journal of Hydrology, 511, 320-334, doi: 10.1016/j.jhydrol.2014.01.061.

Gupta, C. P., M. Thangarajan, and V. V. S. Gurunadha Rao (1985), Evolution of regional hydrogeologic setup of a hard rock aquifer through R-C analog model, Ground Water, 23, 331-335.

Harbaugh, A. W., and M. G. McDonald (1996), User's documentation for MODFLOW-96, an update to the U.S. Geological Survey modular finite-difference ground-water flow model, 56 pp, USGS.

Howard, K. W. F., and J. Karundu (1992), Constraints on the exploitation of basement aquifers in East Africa. Water balance implications and the role of the regolith, Journal of Hydrology, 139, 183196.

IGN (2000), Topographic map TOP25 1016ET, Saint-Cast-le Guildo/Cap Fréhel (GPS), 1/25 000. Jiménez-Martinez, J., L. Longuevergne, T. L. Borgne, P. Davy, A. Russian, and O. Bour (2013), Temporal and spatial scaling of hydraulic response to recharge in fractured aquifers: Insights from a frequency domain analysis, Water resources research, 49, 3007-3023, doi: 10.1002/wrcr.20260. Lachassagne, P., C. Golaz, J.-C. Maréchal, D. Thiery, F. Touchard, and R. Wyns (2001), A methodology for the mathematical modelling of hard-rock aquifers at catchment scale, based on the geological structure and the hydrogeological functioning of the aquifer, in XXXI IAH Congress : New approaches characterising groundwater flow, edited by K.-P. Seiler and S. Wohnlich, pp. 367-370, AA Balkema, Munich.

Lachassagne, P., R. Wyns, and B. Dewandel (2011), The fracture permeability of hard rock aquifers is due neither to tectonics, nor to unloading, but to weathering processes, Terra Nova, 23, 145-161, doi: 10.1111/j.1365-3121.2011.00998.x.

Lenck, P.-P. (1977), Données nouvelles sur l'hydrogéologie des régions à substratum métamorphique ou éruptif. Enseignements tirés de la réalisation de 900 forages en Côte-d'Ivoire, Comptes rendus de l'Académie des Sciences de Paris, Série II a, 285, 497-500. 
Lubczynski, M. W., and J. Gurwin (2005), Integration of various data sources for transient groundwater modeling with spatio-temporally variable fluxes. Sardon study case, Spain, Journal of Hydrology, 306, 71-96, doi: 10.1016/j.jhydrol.2004.08.038.

Maidment, D. (1993), Handbook of Hydrology, McGraw-Hill ed., New York.

Maréchal, J.-C., B. Dewandel, S. Ahmed, L. Galeazzi, and F. K. Zaidi (2006), Combined estimation of specific yield and natural recharge in a semi-arid groundwater basin with irrigated agriculture, Journal of Hydrology, 329, 281-293, doi: 10.1016/j.jhydrol.2006.02.022.

Maréchal, J.-C., B. Dewandel, and K. Subrahmanyam (2004), Use of hydraulic tests at different scales to characterize fracture network properties in the weathered-fractured layer of a hard rock aquifer, Water Resources Research, 40, W11508, doi: 10.1029/2004WR003137.

Mazi, K., A. D. Koussis, P. J. Restrepo, and D. Koutsoyiannis (2004), A groundwater-based, objectiveheuristic parameter optimisation method for a precipitation-runoff model and its application to a semi-arid basin, Journal of Hydrology, 290, 243-258, doi: 10.1016/j.jhydrol.2003.12.006.

McFarlane, M. J. (1992), Groundwater movement and water chemistry associated with weathering profiles of the African surface in parts of Malawi, in Hydrogeology of Crystalline Basement Aquifers in Africa Geological Society Special Publication, edited by E. P. Wright and W. G. Burgess, p. 101-129.

Molénat, J., P. Davy, C. Gascuel-Odoux, and P. Durand (1999), Study of three subsurface hydrologic systems based on spectral and cross-spectral analysis of time series, Journal of Hydrology, 222, $152-164$.

Penman, H. L. (1948), Natural evaporation from open water, bare soil and grass, Proc. R. Soc. London, Ser. A, 193, 120-145.

Rushton, K. R., and J. Weller (1985), Response to pumping of a weathered-fractured granite aquifer, Journal of Hydrology, 80, 299-309.

Taylor, R. G., and K. W. F. Howard (1999), The influence of tectonic setting on the hydrological characteristics of deeply weathered terrains: evidence from Uganda, Journal of Hydrology, 218, 44-71.

Taylor, R. G., and K. W. F. Howard (2000), A tectono-geomorphic model of the hydrogeology of deeply weathered crystalline rock: evidence from Uganda, Hydrogeology Journal, 8, 279-294.

Vittecoq, B., P. Lachassagne, S. Lanini, and J.-C. Maréchal (2010), Assessment of Martinique (FWI) water resources: effective rainfall spatial modelling and validation at catchment scale, Revue des Sciences de l'Eau, 23, 361-373.

Wright, E. P. (1992), The hydrogeology of crystalline basement aquifers in Africa, in Geological Society Special Publication, edited by E. P. Wright and W. G. Burgess, p. 1-27. 
528

529

530

531

532

533

534

535
Wyns, R., J.-M. Baltassat, P. Lachassagne, A. Legtchenko, J. Vairon, and F. Mathieu (2004), Application of Proton Magnetic Resonance Soundings to groundwater reserve mapping in weathered basement rocks (Brittany, France), Bulletin de la Société Géologique de France, 175, 21-34.

Zhou, H., J. J. Gómez-Hernández, and L. Li (2014), Inverse methods in hydrogeology: Evolution and recent trends, Advances in Water Resources, 63, 22-37, doi: 10.1016/j.advwatres.2013.10.014. 


\section{Appendix 1}

537 In order to validate this new AdVar criterion, the respective behaviours of Var and AdVar were

538 compared on a theoretical example. Perfect sinusoidal curves of heads $(\mathrm{h})$ as a function of time in 539 days (d) with different amplitudes were compared. From the equation of a sinusoid (Equation 3), a 540 reference curve was calculated with an amplitude (a) of $10 \mathrm{~m}$ and a mean value $(\mathrm{m})$ of $0 \mathrm{~m}$, to act as 541 the "observed data".

$542 \quad h=a \cdot \sin \left(\frac{2 \pi}{p} d\right)+m$

543 The period (P) was fixed at 365.25 days to follow an annual variation, and the total duration was set

544 at 30 years. This reference curve was then compared to various "model" curves, with varying $\mathrm{m}$ and

545 a. The "m" parameter varied between 0 and $10 \mathrm{~m}$, and the "a" parameter between 0 and $20 \mathrm{~m}$.

546 With $\mathrm{m}=0$ and $\mathrm{a}=10$, the model curve is identical to the reference curve, and the quality-of-fit-

547 criterion should be equal to zero, both for AdVar and for Var. The distinct behaviours of Var and 548 AdVar with varying " $m$ " and "a" are shown in Figure 9.

Figure 9. Var (grey line) and AdVar (black line) values obtained by comparing perfect sinusoidal shapes to a reference sinusoidal curve with a zero mean $(m)$ and an amplitude $(a)$ of $10 \mathrm{~m}$. Results are shown as a function of " $a$ " from 0 to 20 (first line) and of " $m$ " from 0 to 10 (second line), changing the values of " $m$ " (first line) and of " $a$ " (second line) in each column

It is clear that AdVar is sensitive only to a variation of "a", not of "m", which is due to the way this criterion has been defined, as it depends only on the amplitude variation, which is particularly useful

558 for the purpose of our research. On the contrary, Var depends on both parameters: whereas the

559 minimum Var value increases with " $m$ ", the AdVar minimum value is always zero when "a" is equal to 560 the observed one. Furthermore, the AdVar values are much more variable when "a" varies than the 
561 Var values: on the first plot with $\mathrm{m}=0$, AdVar varies between 0 and 400 as "a" varies between 0 and

562 20, and Var between 0 and 50. This shows the advantage of AdVar with respect to Var: it is more

563 precise on amplitude variations than Var. When all values of Var and AdVar are averaged over the total number of piezometers for each model, it is easier to compare two distinct models when these quality-of-fit values are clearly distinct from one model to another. 
567

568

569

570

571

572

573

574

575

576

577

578

579

580

581

582

583

584

585

\section{Appendix 2}

The results of the two quality-of-fit criteria for the 36 piezometers (average Var and AdVar values for each simulation) are presented exhaustively: Figure 10 and Figure 11, show the evolution of Var (first line) and AdVar (second line) as a function of Rech (Figure 10) and Sy2 (Figure 11). Each column corresponds to a distinct value of Sy1 and each curve to a distinct value of Sy2 (Figure 10) and Rech (Figure 11). The scale of the $\mathrm{Y}$ axis is chosen identical for all Var, and for all Advar, thus some curves that are too high for the scale disappear from the plots: the focus is on low criterion values.

Note that the lowest Var and AdVar values are obtained mostly for the highest recharge (Rech) parameter.

For Var, the curve shapes in Figure 10 are very similar, generally showing a better fit towards the high recharge values and for the highest Sy2. For Sy1 up to $3 \%$, the best fit is obtained for a recharge of $100 \% \mathrm{Eff}_{\mathrm{R}}$, but for higher Sy1 values, this recharge is lower and varies between 80 and $100 \% \mathrm{Eff}_{\mathrm{R}}$. For AdVar, the analysis is more delicate, as the Sy2 curves in Figure 10 do not show a homogeneous behaviour. For Sy1 up to $3 \%$, the lowest AdVar values are obtained for the lowest recharge. On the contrary, when Sy1 increases, except for the lowest Sy2 values, most of the lowest AdVar values are obtained with the maximum recharge, and here the difference between 80,90 and $100 \% \mathrm{Eff}_{\mathrm{R}}$ is greater than for Var.

Figure 11 shows distinct behaviours for Var and AdVar as functions of Sy2. Judging by the Var criterion only, one might conclude that the best fit would be obtained with the highest values of Sy2, even above $15 \%$, as shown in section 4.3. With the AdVar criterion however, the best fit for Sy2 is between 4 and $5 \%$, which, although quite high for a fractured layer, is more realistic.

Figure 10. Results of the quality-of-fit criteria Var and AdVar as functions of the recharge values on the $X$ axis, each curve representing a distinct Sy2 value, and each column a distinct Sy1 value 
593

594 Figure 11. Results of the quality-of-fit criteria Var and AdVar as functions of the Sy2 values on

595 the $X$ axis, each curve representing a distinct recharge value, and each column a distinct Sy1

596 value

597 


\section{Figures}

599

600

601

602

603

604

605

606

607

608

609

610

611

612

613

614

615

616

617

618

619

620

621

Figure 12. Location of the study area (within the grey-shaded polygon), the meteorological

stations (stars), and the only gauging station (square)

Figure 13. Geometry of the finite-difference model, boundary conditions, thickness of layer 1

(white: zero thickness) and location of the piezometers with their respective numbers

Figure 14. Precipitation $(P)$, calculated real evapotranspiration (RET) and effective rainfall

$\left(E_{R}\right)$ used for each model time-step

Figure 15. Measured water table in two types of piezometers: P17 in the fractured layer and

P26 in the saprolite

Figure 16. Examples of piezometric variations for $P 26$ within the saprolite and $P 17$ within the fractured layer. Two model results corresponding to the best Var and AdVar values are compared to the observed data

Figure 17. Observed and modelled heads for $P 26$, testing various recharge values

Figure 18. Observed and modelled heads on $P 26$, testing various $K$ values

Figure 19. Schematic view of the main results showing the observed and simulated piezometric amplitude variation for the two cases of a water table in the saprolite and in the fractured layer. 
623

624

625

626

627

628

629

630

631

632

633

634

635

636

637

638

639

640

641

642

643

644

645

646

Figure 20. Var (grey line) and AdVar (black line) values obtained by comparing perfect

sinusoidal shapes to a reference sinusoidal curve with a zero mean $(m)$ and an amplitude (a)

of $10 \mathrm{~m}$. Results are shown as a function of " $a$ " from 0 to 20 (first line) and of " $m$ " from 0 to

10 (second line), changing the values of " $m$ " (first line) and of " $a$ " (second line) in each

column

Figure 21. Results of the quality-of-fit criteria Var and AdVar as functions of the recharge values on the $X$ axis, each curve representing a distinct Sy2 value, and each column a distinct Sy1 value

Figure 22. Results of the quality-of-fit criteria Var and AdVar as functions of the Sy2 values on the $X$ axis, each curve representing a distinct recharge value, and each column a distinct Sy1 value

\section{Tables}

Table 4. Var values (in $\mathrm{m}^{2}$ ) obtained for all Sy1 and Sy2 values. Yellow: minimum values;

orange, red and light brown respectively: classes around the minimum, with an increase of Var of $5 \%$ of the total variation range between two successive classes

Table 5. AdVar values (in $\mathrm{m}^{2}$ ) obtained for all Sy1 and Sy2 values. Yellow: minimum values; orange, red and light brown respectively: classes around the minimum, with an increase of AdVar of $0.5 \%$ of the total variation range between two successive classes

Table 6. Var and AdVar values (in $\mathrm{m}^{2}$ ) for piezometers P26 and P17 with two Sy set of values 
New submission of HYDROL21465 / HYDROL21465R1 to "Journal of Hydrology"

\begin{tabular}{|c|c|c|c|c|c|c|c|c|c|}
\hline & \multicolumn{9}{|c|}{ Sy1 } \\
\hline & $1 \%$ & $2 \%$ & $3 \%$ & $4 \%$ & $5 \%$ & $6 \%$ & $7 \%$ & $10 \%$ & $15 \%$ \\
\hline $1 \%$ & 116 & 95 & 90 & 90 & 94 & 99 & 106 & 128 & 161 \\
\hline $2 \%$ & 105 & 89 & 85 & 86 & 91 & 97 & 104 & 127 & 161 \\
\hline $3 \%$ & 99 & 85 & 82 & 85 & 90 & 96 & 103 & 126 & 161 \\
\hline $4 \%$ & 95 & 82 & 80 & 83 & 89 & 95 & 103 & 126 & 161 \\
\hline $5 \%$ & 92 & 80 & 79 & 82 & 88 & 95 & 102 & 126 & 161 \\
\hline $6 \%$ & 90 & 79 & 78 & 81 & 87 & 94 & 102 & 126 & 161 \\
\hline $7 \%$ & 88 & 77 & 77 & 80 & 86 & 94 & 101 & 126 & 161 \\
\hline $10 \%$ & 83 & 73 & 74 & 78 & 85 & 92 & 101 & 125 & 161 \\
\hline $15 \%$ & 78 & 69 & 70 & 75 & 83 & 91 & 99 & 125 & 161 \\
\hline
\end{tabular}


New submission of HYDROL21465 / HYDROL21465R1 to "Journal of Hydrology"

\begin{tabular}{|c|c|c|c|c|c|c|c|c|c|}
\hline & $1 \%$ & $2 \%$ & $3 \%$ & $4 \%$ & $5 \%$ & $6 \%$ & $7 \%$ & $10 \%$ & $15 \%$ \\
\hline $1 \%$ & 166.2 & 63.6 & 35.1 & 23.5 & 17.6 & 14.1 & 12.0 & 9.2 & 8.3 \\
\hline $2 \%$ & 118.3 & 41.3 & 22.1 & 15.0 & 11.7 & 9.9 & 9.0 & 7.9 & 8.2 \\
\hline $3 \%$ & 101.2 & 34.5 & 18.5 & 12.8 & 10.3 & 9.1 & 8.5 & 8.1 & 8.8 \\
\hline $4 \%$ & 93.0 & 31.7 & 17.3 & 12.3 & 10.2 & 9.2 & 8.7 & 8.6 & 9.4 \\
\hline $5 \%$ & 88.6 & 30.5 & 16.9 & 12.3 & 10.4 & 9.5 & 9.1 & 9.1 & 10.0 \\
\hline $6 \%$ & 86.2 & 30.0 & 16.9 & 12.5 & 10.7 & 9.9 & 9.5 & 9.5 & 10.5 \\
\hline $7 \%$ & 84.8 & 29.9 & 17.1 & 12.7 & 11.0 & 10.2 & 9.9 & 10.0 & 10.9 \\
\hline $10 \%$ & 83.4 & 30.1 & 17.7 & 13.5 & 11.9 & 11.2 & 10.9 & 11.0 & 11.9 \\
\hline $15 \%$ & 83.9 & 30.9 & 18.6 & 14.4 & 12.8 & 12.2 & 11.9 & 12.1 & 12.9 \\
\hline
\end{tabular}

649

650 


\section{Highlights}

652 - Quantitative evidence that the saprolite layer is more capacitive than the fractured one

653 - New quality-of-fit criterion, AdVar, based on the piezometric amplitude variations

654

655 